\title{
DRAWING A STRUCTURAL MODEL BY THE MOST EFFECTIVE COMPONENTS ON OPTIMAL GLOBAL MARKETING
}

\section{Farzad Nazari}

Fnazari120@gmail.com Department of Management, Payame Noor University, Tehran, Iran.

\section{Soodabeh Najafi} sodinajafi@gmail.com Islamic Azad University, Iran.

Farnaz Shahsavari Farnazshahsavari5@gmail.com Islamic Azad University, Iran.

Aylar Zeynalzadeh Ze.aylar@gmail.com University of Tehran, Iran

\section{ABSTRACT}

Goal: International trade and success in this field is one of the most important goals based on the profitability and reputation among different companies and organizations, in which the most important tool is optimal global and international marketing; therefore, this research aims at drawing the model of structure by the components influencing optimal global marketing.

Design / Methodology / Approach: To this end, 385 experts, professionals, and scholars in this field, whose number was determined by the Cochran formula, completed a researcher-made questionnaire. In this paper used the structural equation method.

Results: The results show that the application of technology, product quality, price, variety and communication (brand) are the five affecting factors on optimal global marketing. In the meantime, the product quality has the greatest effect on optimal global marketing, and with exception of the diversity which is the indirect predictor of optimal global marketing, other variables directly predict this indicator, as well as the results of fitting the model showed that the created model is an efficient and reliable tool for investigating the components affecting the identification of global optimal marketing.

Limitations of the investigations: This research has been done in Iran, Naturally, it has to be validated for use elsewhere in the world, it is possible that it may not be cited elsewhere or give different results.

Practical implications: Results of this study can be use to increase sales and supply rates of products Because by knowing the best marketing agents can increased the rate of supply of goods and products.

Originality / Value: It has not been studied so far and the results of this article can be used all over the world.

Keywords: Global Marketing; Product Quality; International Trade; Technology. 


\section{INTRODUCTION}

The one thing that drives companies out of crises is marketing, and over the past twenty years, marketing has consistently emphasized the impact of marketing on corporate success, with marketing always being a factor in corporate success. That is, it is emphasized that marketing activity must be integrated into the management process at an early stage. Employers must incorporate one of their marketing strategies into their business profits as well as combine computerization and soft marketing. Applications have been tangible in recent years (Farshchi and Zanjani, 2016).

The best criterion for defining marketing strategies minus resources is the one that can generate value in the market (Hooley et al., 2005). Marketing resources should therefore be cited as sources that can rapidly provide or maintain customer relationships, marketability, human resources and tools that are widely accepted by the market. In the market.

On the other hand, to support marketing activities, marketing support resources, such as market-oriented guidance and capabilities, are used primarily to directly impact competitive advantage, performance-based marketing strategies by organizational resources, resources. Human resources and marketing capacities and resources are controlled. Understanding many factors in the evaluation process makes marketing strategies very difficult ( $\mathrm{Lin}$ and $\mathrm{Wu}$, 2008).

Paid, Nicoletti Junior et al. (2018) reviewed a study entitled ERP Implementation Project in a Beer Producer: Their Research was a Case Study in Brazil on Brewery Locations Including 6 Business Planning Systems Organizational resources (ERP) was the method of collecting information in their study through interview and questionnaire. They concluded that quality attribute is a differential function (Nicoletti Junior et al., 2018).

Soares et al. (2017) A study by title of the SERQUAL model by government higher education services found that tangibility was reported as the single most positive among the five proposed dimensions (Soares et al., 2017).

Keller et al. (2017) conducted a monetary study on strategic tools and business modeling in an information technology firm. They believe that most startups that are small in the information and technology sector have problems with increasing their jobs and employing more people, as well as expanding their service products. Their three-stage study aims to use strategic tools and business models. Work on a small portion of the software entered into a major market competition and barriers to entry, as well as their qualitative research. The data were collected through a questionnaire study, their data analysis tools PESTEL, Porter 5 and The matrices were SWOT, including the main results of new technologies, media release, service The complementary and supportive partnerships adapted (Keller et al., 2017).

Roy (2010) Towards a monetary study as an optimization model for cross-functional decision making: A business computational information approach. He believes that the latest technologies reinforce the relationship between production performance and marketing. Also, his study found that in many decision-making processes they do not consider only the dynamic aspect of the market, he has attempted to provide a The gap between marketing and integrated manufacturing problem optimizes advanced planning system by developing a mathematical model (Roy, 2010).

Different business organizations apply specific strategies to increase revenue and business success in order to maximize profits and financial and income opportunities (Federo and Carranza, 2016). In the current situation, identification of customer behavior and their interests and perspectives is essential for business success and economic competitiveness. The pre-existing goal in this field is to use a tool to change the customer's interests and tastes to gain power and make fundamental changes (Solomon, 2013). As a result, companies and manufacturing and services units keep their commercial and competitive importance over time by utilizing tools and expertise in this field (Martínez-Cañas et al., 2016). To succeed in producing a good and high quality product, there are a lot of factors that, if applied properly, the productive success and work progress can be experienced and predicted in that area (Bhuiyan, 2011). In existence of many rivals in the global market, unit and commercial companies survival are increasingly important and in the center of attention; during this period, companies based their ultimate goal on survival (Karras, 2013) and put their most important goal on applying sales strategies based on increasing customer motivation for product purchases. According to marketing advisers, motivation is an internal movement that drives customers and audiences toward specific products. Therefore, the incentive to purchase is an essential element in development and advancement of the economic and commercial goals of manufacturing and service companies (Maecker et al., 2016). As noted, obtaining customer satisfaction and attraction is one of the most important and essential business plans and also progress in the business process and earnings (Boateng and Narteh, 2016). It is therefore clear that retaining customer loyalty and attracting other customers is the key to successful business (Ponder et al., 2016). Major marketing techniques, and especially mixed marketing, are based on the 
principles of competition, attraction and selection of target society. In this mode of business, the target community is selected and explained to maintain and increase the quantity of specific marketing and commercial programs (Belz and Peattie, 2010). This principle in political marketing is done by applying the same techniques but based on the acquisition of votes, in a way that the basic principle is gaining trust and support of voters more than earning (Wasserfallen, 2013). Various studies have shown that plans by various groups in the political, economic, commercial, social and other fields, with the aim of changing the views of other audiences towards their own targeted programs applied or specific programs are used which are aimed at maintaining the loyalty of their customers (Sharma et al., 2006). One of the most important techniques in this field is to attract and retain customers by using international social media and existing programs; this communication system links the different strata and is the best and most suitable place for applying and conducting ads or, in other words, marketing types (Andrew, 2016). The reason for the high importance of social media is trying to get the most customer through the marketing. The excellence in gaining a competitive, political, and situational market forms the basic concept of marketing that has its own specific principles and programs. Marketing in a competitive business form is based on the fundamental principles of competition in order to obtain the most financial success and overall economics, and the program and focus in this system is based on the commercialization of financial and commercial markets (Borio et al., 2014), therefore, in current economic conditions and with having large commercial competitors, maintaining the structure and capability of the international community is key to business success. One of the most important tools of international success for different organizations is the application of optimal global marketing at various levels, and due to this matter, the research seeks to identify and assess the most important components affecting the global business and marketing. In the present study, the effect of the most effective component on global marketing and outline of a general structure in this field was investigated.

\section{METHODS}

Structural Equation Modeling (SEM):

Structural Equation Modeling (SEM) is a case of causal modeling that involves a set of mathematical equations, computer algorithms, and statistical methods that communicate between case and data segments (Kaplan, 2008). SEM structural equations include confirmatory factor analysis and confirmatory composite analysis, path analysis, partial least squares path modeling, and growth modeling
(Kline, 2011), which should not be confused with definitions of economic models. Relationships between structures of a structural equation modeling may be employed through more involved equations or independent regression such as using LISREL for estimation (Kline, 2011). In the social sciences, the use of the structural equation approach is usually recommended because it is capable of establishing a relationship between unsupervised structures (Hancock, 2003). This research is descriptive and correlative and has a practical nature. Field and library are two methods which have been used to collect information and complete the questionnaire. The library method has been used to collect and complete theoretical foundations of the research. To study the research hypotheses and statistical analysis, the field method has been used and the questionnaire has been completed.

\section{Comprehensive statistical and sampling}

All experts were selected as the statistical population of this study, professionals, scholars and people who are knowledgeable about the field of global marketing or engaged in. Due to the dispersion of research sample and the lack of access to all members of the community, the available sampling method was used. The Cochran formula was used to determine the number of sample members:

In this study, Cochran formula was used to determine sample size

$n=\frac{z^{2} p q}{d^{2}}$

Due to the wide variety of research population in the one hand, and on the other hand, because the number of studied communities is limited, the second Cochran formula is used to determine the minimum sample size required, as following:

$n=\frac{(1 / 96)^{2}(0 / 5)(1-0 / 5)}{(0 / 5)(1-0 / 5)} \approx 385$

In which:

$\mathrm{n}=$ minimum required sample size

$\mathrm{p}=$ attribute distribution ratio in society

$z \alpha / 2=$ The value obtained from the standard normal distribution table (in this study and taking into account the error value of 0.05 , the value obtained from the standard distribution table is $1 / 96)$. 
$d=$ the error accepted by the researcher or the tolerable interval from the estimated parameter is considered (usually in the social sciences is equal to 0.05) (Rafipour, 2009).

The point to be made with regard to this formula is that, if $p$ is not available, a value of 0.5 can be considered (Azar and Momeni, 2008), in which case, This formula will give the largest possible value, which is considered to be 0.5 in this study. By placing the parameters in the formula, the sample size required will be 384.16 , which will be based on the analysis.

Research Instruments

\section{Effective Components on Optimal Global Marketing:}

In this regard, a 30-items questionnaire was designed that its content validity was confirmed by 3 faculty professors and Cronbach's alpha coefficient was used to assess the validity of the questionnaire. In order to investigate the validity of the questions and the main components of the questionnaire, factor analysis was first performed to determine the validity of the construct. The factor structure of the questionnaire was determined: The size of the KMO sampling adequacy is the test of variance value in the data which can be explained by factors. The more KMO is closer to 1 , the better is KMO. According to Kesser, KMO higher than 0.9 is excellent, 0.8 domain is fair, in 0.7 domain is better than average, in the 0.6 range is modest, in the range of 0.5 bad and less than it is unacceptable. (Hooman, 2009). The $\mathrm{KMO}$ rate for the effective components questionnaire in optimal global marketing was 0.911 , which is excellent. Also, the amount of $\mathrm{Xi}$ is twice that of 2883 with a significance of 0.00 . Because the level of significance is less than 0.01 . The ability of data to be factorized and performing the factor analysis is verified. Factor analysis revealed five main factors and components for this questionnaire; after final modification of questions, the number of questions was reduced to 25 , and these dimensions included: application of technology, product quality, price, variety and communication (brand). The Internal consistency of articles for the whole test performed by Cronbach's alpha is equal to 0.888 and for the subscale of technology, product quality, price, variety and communication (brand), respectively, are equal to $0.814,0.799 ; 0.886,0.851$ and 0.794 . Considering that the size of Cronbach's alpha for the whole questionnaire and all subscales is more than 0.7 , this questionnaire is an excellent tool for measuring the effective factors on optimal global marketing.

\section{RESULTS AND DISCUSSION}

Investigating the relationship between optimal global marketing components

In this section, by presenting the presented structural model of the research, the relationship between the research components in terms of meaningful relationship was investigated. It is presented in Table 1.

Table 1 which examines the correlation between research variables, represents a significant positive correlation between all the components associated with optimal global marketing including technology, product quality, price, variety, and communications (brand). There is also a significant positive relationship between all components. With the exception of the price and diversity relationships which are significant at the level of 0.05 , the remaining have significantly positive relationships at the level of 0.01 .

In order to evaluate the model, structural equation modeling was used. According to McCullum (1992), first, all likely direct and indirect paths of independent variables (exogenous) and endogenous and dependent variables were evaluated. The proposed structural model in this study consists of five latent factors that technology application, product quality, price, diversity and communication (brand) as independent variable and optimal global marketing as a dependent variable were evaluated. The structural model of the research is presented in Figure 1.

The strongest component affecting the optimal global marketing is the product quality $(P<0.01)$. The factors such

Table 1. Correlation matrix between the variables

\begin{tabular}{|c|c|c|c|c|c|c|c|c|}
\hline No. & Variable & Mean & SD & Technology & $\begin{array}{c}\text { Quality of } \\
\text { Products }\end{array}$ & Price & Variety & $\begin{array}{c}\text { Communications } \\
\text { (Brand) }\end{array}$ \\
\hline 1 & Technology & 16.4 & 2.11 & 1 & & & & \\
\hline 2 & Quality of Products & 13.5 & 2.01 & ${ }^{* *} 0.53$ & 1 & & & \\
\hline 3 & Price & 17.4 & 2.29 & ${ }^{* *} 0.69$ & ${ }^{* *} 0.35$ & 1 & & \\
\hline 4 & Variety & 13.6 & 2.05 & ${ }^{* *} 0.39$ & ${ }^{* *} 0.43$ & ${ }^{*} 0.26$ & 1 & \\
\hline 5 & Communications (Brand) & 15.6 & 2.17 & ${ }^{* *} 0.55$ & ${ }^{* *} 0.61$ & ${ }^{* *} 0.41$ & ${ }^{* *} 0.48$ & 1 \\
\hline
\end{tabular}

$* * \mathrm{P}<1 * \mathrm{P}<05$ 
as technology, price and communication include other variables that are desirable in addition to the quality of the product which directly predicts the optimal global marketing $(P<0.01)$. The variety is indirect predictor of optimal global marketing also the fit of all the factors in the structural model of the research was considered. Also, the atlest squares errors were determined:

Table 2 shows the degree of fitness of the model. Structural equations modeling (SEM) has some fitness indicators and a structural model. The most common method for estimating the best fitness in SEM is called the maximum probable method. The fitness statistics set for the 5-factor models is as follows: $x^{2}$, AGFI (Adjusted Goodness of Fit Index), GFI (Goodness of Fit Index), CFI (Comparative Fit Index), and RMSEA (Root Mean Square Error of Approximation) was measured in this model.
The closer two AGFI and GFI indicators to one, the more complete fitness of the model and the low value of RMSEA indicates desired fitness. Desirability of CFI indicates higher comparative fitness of the model (Nadi and Akbari, 2013).

Considering that $\mathrm{AGFI}=0.91, \mathrm{GFI}=0.90$ and $\mathrm{CFI}=0.88$ while in these indicators, the closer value to 1 indicates the more desired fitness of the model and also due to RMSEA $=0.06$ which should be closer to zero, therefore, this model has a very suitable fitness and all structures are significant and are consistent to the model. In the following, we discuss the direct and indirect effects of existing factors, these are presented in Table 1.

The results of Table 3 show that the components quality, technology, price, diversity and communications $(0.37,0.34,0.29,0.11$ and 0.25$)$ have direct effect on

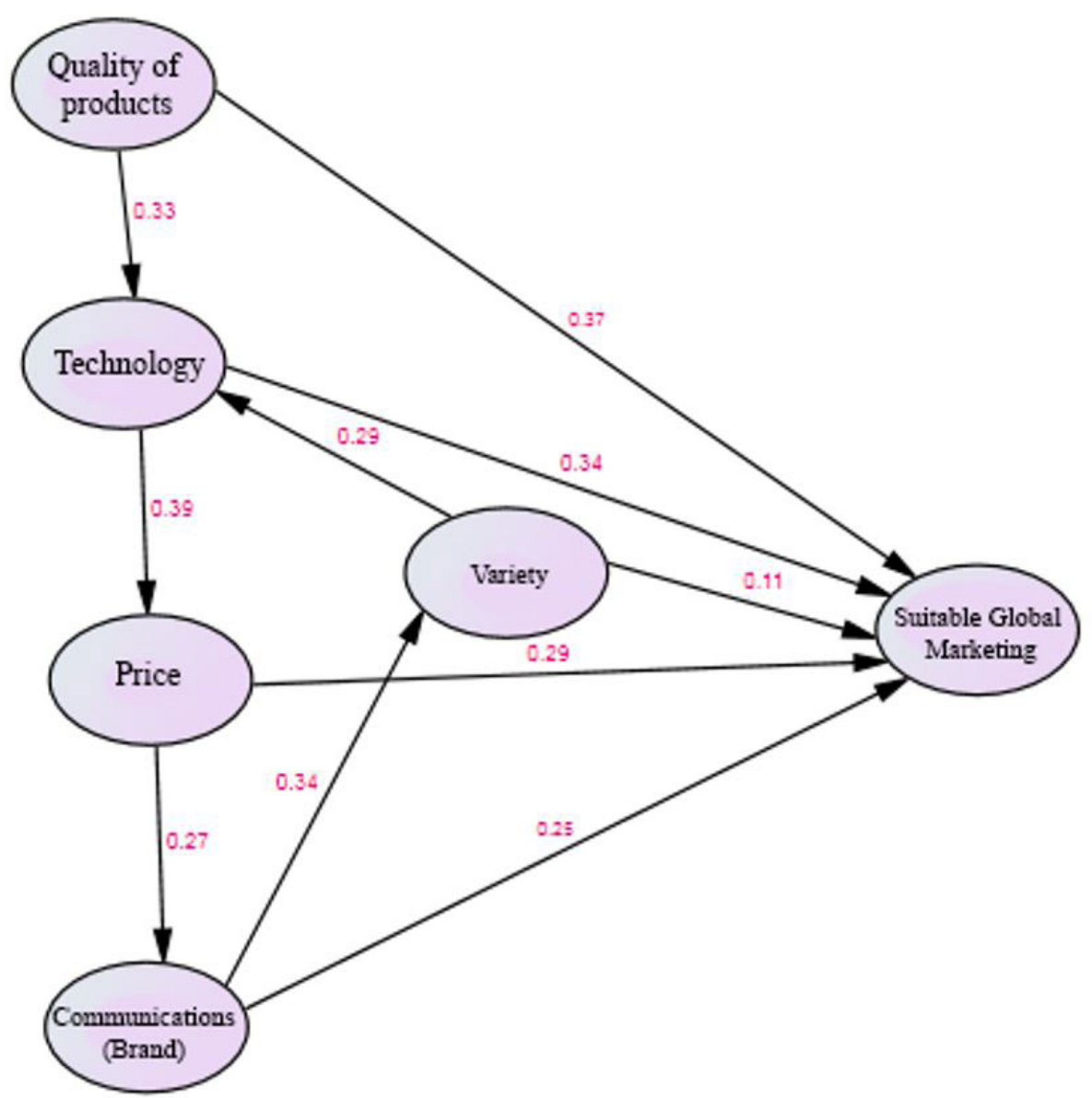

Figure 1. The structural model of the components of optimal (suitable) global marketing

Table 2. Structural Equation Modeling Fitness Indicators

\begin{tabular}{|c|c|c|c|c|c|c|}
\hline Values & $\begin{array}{c}\text { Statistical } \\
\text { Indicators }\end{array}$ & $\mathbf{x}^{\mathbf{2}}$ & AGFI & GFI & CFI & RMSEA \\
\hline & Fitness & 512 & 0.91 & 0.90 & 0.88 & 0.06 \\
\hline
\end{tabular}


Table 3. Direct and indirect effects of exogenous variables on the variables

\begin{tabular}{|l|c|c|}
\hline \multicolumn{1}{|c|}{ Structural relations } & Direct effect & Indirect effect \\
\hline Quality of products & 0.37 & 0.11 \\
\hline Technology & 0.34 & 0.09 \\
\hline Price & 0.29 & 0.08 \\
\hline Variety (Diversity) & 0.11 & 0.21 \\
\hline Communications (Brand) & 0.25 & 0.06 \\
\hline
\end{tabular}

optimal global marketing and their indirect effects are $0.11,0.09,0.08,0.21$ and 0.06 , respectively. Therefore, the factor quality has the highest direct effect and diversity has the highest indirect effect on optimal global marketing.

\section{CONCLUSION}

Business success and excellence in economic positions are the primary goals and the index of enterprises and firms accordingly (Marten et al., 2015). Also, profitability and pragmatism are considered as a construct that guarantees and predicts the survival and continuity of the organization and its respective organs (Albrecht et al., 2015). In the present age, the world experiences the complexity of the organization and the existence of close relationships in its domain with the integration of communication systems and the interference of direct roles among various occupations (McInerney and Koenig, 2011). In the current situation, when various organizations work at different levels to attract customers and gain exclusive position, marketing is the main application and the guarantor of sales and commercial success in this area. At the global marketing level, the basic principles of this structure should lead to the attraction of international audiences and importing companies in different sectors, which will only be achieved if the needs and demands of customers and intermediary companies are met (Lin and Chang, 2017). Based on this principle, various companies try to identify and meet the needs of their customers in order to improve their applicability in their products and structures in order to satisfy the needs of the international structure, but according to this matter, global marketing is required to identify products and services, it is possible to make commercial success in this area and, in accordance with the basic principle of commercial law, marketing is as important as the product itself. In this regard, due to the importance of such topics, the aim of this study was to identify the components affecting optimal global marketing and through the structural modeling, the most important components influencing this level of marketing include technology, product quality, price, diversity and communication (Brand identification) and it was determined that among the identified components, the product quality has the highest direct effect and diversity has the highest indirect effect on the optimal global marketing. These results are consistent with Lin and Chang (2017) where the quality and utilization of day-to-day technology are of the most important factors in the success of the sale of a product or brand, highlighting the importance of the brand of a company and its history in successful marketing. It also refers to the fact that in successful commercial marketing of goods and services and at various levels, the basic factors such as product quality and basic structures such as technology utilization, brand communication, and so forth, affect their recognition and application in international trade and thus, business success and economic power can be gained in various fields.

\section{RESULT}

This research was conducted by examining and prioritizing the factors influencing global optimum marketing.

1- The priority of the present study was structural equations

2- technology, product quality, price, variety and communication (brand) are the five affecting factors on optimal global marketing.

3- Diversity factor had indirect effect but other factors had direct effect

4- Product quality factor had the most impact on global optimum marketing

Future Research:

1- Neural network weighting method can be used to prioritize the factors influencing global optimum marketing and compare the results.

2- Hierarchical analysis can also be used to prioritize the factors influencing global optimum marketing and compare the results.

\section{REFERENCES:}

Albrecht, S.L., Bakker, A., Gruman, J. et al. (2015), “Employee engagement, human resource management practices and competitive advantage: An integrated approach", Journal of Organizational Effectiveness: People and Performance, Vol. 2, No. 1, pp. 7-35. http://dx.doi.org/10.1108/JOEPP-082014-0042.

Andrew, S.T. (2016), "The role of digital and social media marketing in consumer behavior", Current Opinion in Psychology, Vol. 10, pp. 17-21. 
Azar, A. and Momeni, M. (2008), Statistics and its Application in Management, 2nd ed., SAMT Publications, Tehran.

Belz, F.M. and Peattie, K. (2010), Sustainability Marketing: A Global Perspective, J. Wiley\&Sons, Glasgow.

Bhuiyan, N. (2011), "A framework for successful new product development", Journal of Industrial Engineering and Management, Vol. 4, No. 4, pp. 746-70. http://dx.doi. org/10.3926/jiem.334.

Boateng, S.L. and Narteh, B. (2016), “Online relationship marketing and affective customer commitment: The mediating role of trust", Journal of Financial Services Marketing, Vol. 21, No. 2, pp. 127-40.

Borio, C., James, H. and Shin, H.S. (2014), The international monetary and financial system: A capital account historical perspective, Bank for International Settlements, Basel, Switzerland.

Farshchi, A. and Zanjani, H.J. (2016), "Presenting a Method for Designing Optimal Marketing Strategy Planning: Decision Making with ANP and TOPSIS", in International Conference on Industrial Engineering and Management, Tehran, Iran, p. 2.

Federo, R. and Carranza, A.S. (2016), “Devising strategic plans to improve organizational performance of intergovernmental organizations", Global Policy, Vol. 8, No. 2, pp. 202-12.

Hancock, G.R. (2003), "Fortune cookies, measurement error, and experimental design", Journal of Modern Applied Statistical Methods, Vol. 2, No. 2, pp. 293-305. http://dx.doi. org/10.22237/jmasm/1067644980.

Hooley, G.J., Greenley, G.E., Cadogan, J.W. et al. (2005), "The performance impact of marketing resources", Journal of Business Research, Vol. 58, No. 1, pp. 18-27.

Hooman, K., Gurgenci, H. and Dincer, I. (2009), "Heatline and 'energy flux vector' visualization of natural convection in a porous cavity occupied by a fluid with temperaturedependent viscosity", Journal of Porous Media, Vol. 12, pp. 265-75.

Kaplan, D. (2008), Structural Equation Modeling: Foundations and Extensions, 2nd ed., SAGE Publications, Thousand Oaks, CA, pp. 79-88.
Karras, G. (2013), "Is fiscal policy more effective during cyclical downturns", Internacional Economic Journal, Vol. 28, No. 2, pp. 255-71.

Keller, F., Daronco, E. and Cortimiglia, M. (2017), "Strategic tools and business modeling in an information technology firm", Brazilian Journal of Operations \& Production Management, Vol. 14, No. 3, pp. 304-17. https://doi.org/ https://doi.org/10.14488/BJOPM.2017.v14.n3.a4

Kline, R. (2011), Principles and Practice of Structural Equation Modeling, 3rd ed., Guilford, New York, NY, pp. 230-294.

Lin, C.T. and Wu, C.S. (2008), "Selecting marketing strategy for private hotels in Taiwan using the analytic hierarchy process", Service Industries Journal, Vol. 28, No. 8, pp. 1077 91.

Lin, H. and Chang, K. (2017), "Key success factors of international market development: An empirical study of the Taiwan bulk shipping industry", Maritime Business Review, Vol. 2, No. 2, pp. 79-98. http://dx.doi.org/10.1108/MABR09-2016-0025.

Maecker, O., Barrot, C. and Becker, J. (2016), "The effect of social media interactions on customer relationship management", Business Research, Vol. 9, No. 1, pp. 133-55.

Martens, P.J., Chateau, D.G., Burland, E.M.J. et al. (2015), "PATHS Equity Team. The effect of neighborhood socioeconomic status on education and health outcomes for children living in social housing", American Journal of Public Health, Vol. 104, No. 11, pp. 2103-13.

Martínez-Cañas, R., Ruiz-Palomino, P., Linuesa-Langreo, J. et al. (2016), "Consumer participation in co-creation: an enlightening model of causes and effects based on ethical values and transcendent motives", Frontiers in Psychology, Vol. 7, pp. 793. http://dx.doi.org/10.3389/fpsyg.2016.00793.

McCullum, C. (1992), Disease and dirt: social dimensions of influenza and syphilis, The Pharos of Alpha Omega AlphaHonor Medical Society, Vol. 55, No. 1, pp. 22-29.

Mclnerney, C.M. and Koenig, E.D. (2011), Knowledge Management (KM) Processes in Organizations: Theoretical Foundations and Practice, Morgan and Claypool, Williston, VT.

Nadi, M.A. and Akbari, A. (2013), Analysis of relationship between interpersonal conflict at work and social competencies on experience of incivility behavior based on 
structural equation modeling", Knowledge \& Research in Applied Psychology, Vol. 14, No. 54, pp. 4-17.

Nicoletti Junior, A., Martens, M. and Oliveira, M. (2018), "ERP Implementation Project in a brewing manufacturer: the quality attribute as a performance differential", Brazilian Journal of Operations \& Production Management, Vol. 15, No. 4, pp. 517-27.

Ponder, N., Bugg, B. and Hansen, J.D. (2016), “The mediating effects of customers' intimacy perceptions on the trustcommitment relationship", Journal of Services Marketing, Vol. 30, No. 1, pp. 75-87. http://dx.doi.org/10.1108/JSM-042014-0117.

Rafipour, F. (2009), Specific Techniques in Social Sciences, 4th ed., Tehran: Sahami Publications.

Roy, S. (2010), “Optimization model for cross-functional decision making: a computational business intelligence approach", Brazilian Journal of Operations \& Production
Management, Vol. 6, No. 1, pp. 37-62. https://bjopm. emnuvens.com.br/bjopm/article/view/BJV6N1_2009_2

Sharma, N., Young, L. and Wilkinson, I. (2006), "The commitment mix: dimensions of commitment in international trading relationships in India", Journal of International Marketing, Vol. 14, No. 3, pp. 64-91.

Soares, M., Novaski, O. and Anholon, R. (2017), "SERVQUAL model applied to higher education public administrative services", Brazilian Journal of Operations \& Production Management, Vol. 14, No. 3, pp. 338-49. https://doi.org/ https://doi.org/10.14488/BJOPM.2017.v14.n3.a7

Solomon, M.R. (2013), "Consumer Behavior: Buying, Having, and Being, 10th ed., Pearson Education, Essex, England.

Wasserfallen, F. (2013), "Political and economic integration in the EU: the case of failed tax harmonization", Journal of Common Market Studies, Vol. 52, No. 2, pp. 420-35.

Received: 14 May 2019

Approved: 31 Oct. 2019

How to cite: Nazari, F., Najafi, S. and Shahsavari, F. et al. (2020), "Drawing a structural model by the most effective components on optimal global marketing", Brazilian Journal of Operations \& Production Management, Vol. 17, No. 1, e2020857. https://doi.org/10.14488/BJOPM.2020.002 